\title{
An efficient ABAQUS solid shell element implementation for low velocity impact analysis of FGM plates
}

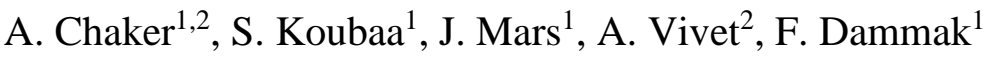 \\ ${ }^{1}$ Electro-Mechanical System's Laboratory (LASEM), National Engineering School of Sfax, \\ B.P 1173-3038, Sfax, University of Sfax, Tunisia \\ ${ }^{2}$ Normandie Univ, ENSICAEN, UNICAEN, CEA, CNRS, CIMAP, 14000 Caen, France \\ Corresponding author: aida.chaker@etu.unicaen.fr
}

\begin{abstract}
The main objective of this paper is to develop a numerical model susceptible to solve the numerical locking problems that may appear when applying the conventional solid and shell finite elements of ABAQUS. This model is based on an hexahedral solid shell element. The formulation of this element relay on the combination of the Enhanced Assumed Strain (EAS) and Assumed Natural Strain (ANS) methods with modified FSDT. The developed element is implemented into the ABAQUS user element (UEL) interface. The performance of this element is demonstrated by different benchmark tests from literature. Our contribution consists on applying a single solid shell element through the thickness direction to predict the low velocity impact behavior on FGM circular plates.
\end{abstract}

Key-words: Solid shell element, free-locking, FGM, low velocity impact

\section{Introduction}

In mechanical engineering, the finite element method is well employed to solve thin structure problems. Therefore, the choice of the finite element must be reliable and robust to obtain accurate results. The conventional finite elements present almost various numerical locking problem, for instance shear and membrane locking when using shell elements [1,2]. For the case of solid element, we distinguish shear, Poisson thickness and volumetric locking $[3,4]$.

To solve these numerical problems, an alternative solid shell element is proposed by Klinkel[5] and Tan and Vu-Quoc[6]. The formulation of this developed element is based on the coupling of the Assumed Natural Strain (ANS) and the Enhanced Assumed Strain (EAS) methods. The ANS method was derived by Bathe and Dvorkin [7] in order to solve transverse shear locking problem. While the EAS method was derived by Simo and Rifai [8] to overcome Poisson thickness and volumetric locking. According to the literature, solid shell element is frequently implemented into home codes [9-11]. Nonetheless, solid shell element is rarely implemented into the finite element commercial code ABAQUS. Li [12] implemented into the VUEL interface of ABAQUS a free-locking and mixed solid shell element with B-bar formulation to simulate nonlinear shell problems.

Actually, composite materials are employed in several engineering applications thanks to their enhanced properties. Nonetheless, conventional composite materials, present a source of delamination and discontinuities because of their multilayered structures. The FGMs are known as heterogeneous composites prepared by combining ceramic and metal in which material properties vary continuously and gradually in the thickness direction. Recently, several numerical studies have been developed to focus on FG shell structure problems [13-21]. However, the FE discretization of the FGM shell structure applying solid shell element remains scarce. Hajlaoui [22] developed an hexahedral solid shell element with nine EAS parameters to study the buckling behavior of FGM structures. Reinoso and Blázquez [23] integrated an 
hexahedral solid shell element in the interface UEL of ABAQUS to model FGM. The development of this element is based on mixed formulation adopting only seven incompatible modes. While Chalal and Abed-Meraim [24] implemented hexahedral solid shell elements SBH5, SBH15 and SBH20 in the commercial finite elements code ABAQUS to simulate FGM structures. Nevertheless, these elements are only suitable for static problems.

In the literature, three shear deformation theories are proposed to study shell structures: The Kirchhoff-Love approach is derived by Dhatt [25]. In this classical theory, the transverse shear deformation is assumed neglected. To improve this theory, Mindlin [26] develop a First Order Shear Deformation Theory (FSDT) in which a constant effect of transverse shear strain is considered along the thickness direction with a shear correction factor (5/6 in the case of isotropic materials). To overcome the limitations of the Reissner-Mindlin theory, a High Order Shear Deformation Theory (HSDT) is derived [27]. In this theory, a parabolic distribution of the transverse shear strain is considered along the thickness direction. In order to obtain the performance of the HSDT with optimal simulation time, a modified FSDT was proposed $[28,29]$ with parabolic shear correction function. In these papers, shell finite elements were employed. However, to the knowledge of authors the modified FSDT theory is not yet developed using solid shell element.

Because of the wide application field of the FGM in biomedical engineering, transportation and aerospace, various structures a subjected to low velocity impact. The impact solicitation is defined as a brief contact between a projectile or concentrated mass and a beam or a plate. Recently, several studies are developed to predict the elasto-plastic behavior of the FGM when using various methods of homogenization: The Tamura-Tamota-Ozowa (TTO) model is widely used [30-33]. This method is based on the plastic response of the metal phase. In addition to the TTO method we distinguish the incremental method [34], the second order method [35] and the self-consistent method [36]. Mori-Tanaka method [37] and the rule of mixture [38] are developed to predict the elastic properties of the inhomogeneous composites.

Numerical and experimental studies of low velocity impact are widely developed [39-42]. Nevertheless, very limited investigations of the low velocity impact response on FGM structures are depicted in literature. Gunes [43] studied the behavior of FGM circular plates under low velocity impact. The used FGM was composed of aluminum alloy (Al 6061) and the ceramic SiC. An elastoplastic behavior of FGM was considered with isotropic hardening. The homogenization was carried out via the user material UMAT interface of the finite element code ABAQUS. The formulation was based on Mori-Tanaka model and self-consistent methods to predict the FGM elastoplastic behavior. The impact finite element model was considered as 2D axisymmetric in which the circular plate was discretized with $10 \mathrm{CAX} 4$ elements in the thickness direction. In [44], numerical and experimental investigations were realized to predict the effect of low velocity impact on A1/SiC FGM circular plates. The FGM homogenization was based on the Mori-Tanaka model to identify the elastic properties and also based on the TTO method in order to describe the plastic part. Simulations were conducted using the finite element code LS-DYNA. Solid element with eight nodes was applied for the discretization of the FG circular plate. To validate the numerical results with experimental works, the authors applied 40 elements in the thickness direction. However, the study of the low velocity impact of the FGM circular plate using only one solid shell finite element through the thickness direction is not yet developed.

The contribution of this paper is to numerically implement a free-locking hexahedral solid shell element into the commercial code ABAQUS using user element (UEL) FORTRAN subroutines. The formulation of the developed element is based on the coupling between the ANS method with modified FSDT and the EAS method with optimal number of parameters. The performance and the robustness of this element are assessed using benchmark tests with 
various geometries and materials. In this work, the scope of this element is extended to expect elastoplastic contact problems such as low velocity impact on functionally graded material (FGM). The simulations are conducted using ABAQUS/Standard. The finite element model consists of a rigid impactor and a circular plate meshed with a single solid shell element though out the thickness direction.

\section{Functionally graded material}

In this paper, the subscript " $m$ " and "c" will be referred to metal and ceramic materials. The volume fraction of ceramic phase varies through the thickness direction as presented in the following expression [45]:

$$
V_{c}(z)=\left(\frac{1}{2}+\frac{z}{h}\right)^{p} ; \quad V_{m}+V_{c}=1
$$

\subsection{Elastic FGM properties}

In this work, The Mori-Tanaka method [37] is applied to predict the elastic properties of the FGM circular plates. The effective bulk modulus $k(z)$ and the effective shear modulus $\mu(z)$ take the following forms

$$
k(z)=k_{m} \frac{1+V_{c}\left(\frac{k_{c}}{a_{1} k_{m}}-1\right)}{1+V_{c}\left(\frac{1}{a_{1}}-1\right)} \quad ; \quad \mu(z)=\mu_{m} \frac{1+V_{c}\left(\frac{\mu_{c}}{b_{1} \mu_{m}}-1\right)}{1+V_{c}\left(\frac{1}{b_{1}}-1\right)}
$$

in which the variables $a_{1}$ and $b_{1}$ are given as

$$
\left\{\begin{array}{l}
a_{1}=1+s_{1}\left(\frac{k_{c}}{k_{m}}-1\right) \\
b_{1}=1+s_{2}\left(\frac{\mu_{c}}{\mu_{m}}-1\right)
\end{array} ;\left\{\begin{array}{l}
s_{1}=\frac{\left(1+v_{m}\right)}{3\left(1-v_{m}\right)} \\
s_{2}=\frac{2\left(4-5 v_{m}\right)}{15\left(1-v_{m}\right)}
\end{array}\right.\right.
$$

Then, the Poisson's ratio and the Young's modulus of the homogenized FGM are written as follows

$$
v(z)=\frac{1}{2} \frac{3 k(z)-2 \mu(z)}{3 k(z)+\mu(z)} \quad ; \quad E(z)=2 \mu(z)(1+v(z))
$$

The FGM mass density is expressed, using the mixtures rule, as following

$$
\rho(z)=V_{m} \rho_{m}(z)+V_{c} \rho_{c}(z)
$$

\subsection{Elastoplastic FGM properties}

In this work, the metal behavior is assumed as elastoplastic with isotropic hardening. The Ludwik power plastic hardening law is considered [37]. The matrix stress $\sigma_{m}$ takes the following expression

$$
\sigma_{m}=\sigma_{Y m}+K_{m} r^{n_{m}}
$$

$\sigma_{Y m}, K_{m}$ and $n_{m}$ are respectively the matrix yield strength, strength coefficient and strain hardening exponent. $r$ is the plastic strain. The FGM has an elastoplastic behavior of the matrix with the Ludwik power plastic hardening law: 


$$
\sigma=\sigma_{Y}+K r^{n}
$$

$\sigma$ is the stress, $r$ is the plastic strain, $\sigma_{Y}(M P a)$ is the yield strength, $K(M P a)$ is the effective strength coefficient and $n$ is the effective strain hardening exponent. Several models were developed to estimate the $\left(\sigma_{Y}, K, n\right)$ parameters. In this study, we considered the self-consistent model [36] in which $\sigma_{Y}, K$ and $n$ are expressed as

$$
\sigma_{Y}=\frac{E}{E_{m}} \sigma_{Y m} \quad ; \quad K=K_{m} \frac{1+V_{c}}{\left(1-V_{c}\right)^{n}} \quad ; \quad n=n_{m}
$$

\section{Elastoplastic constitutive equations}

The Green-Lagrange strain tensor is decomposed into two parts, elastic $\mathbf{E}^{e}$ and plastic $\mathbf{E}^{p}$ as:

$$
\mathbf{E}=\mathbf{E}^{e}+\mathbf{E}^{p}
$$

The elastic and plastic parts are decoupled. This hypothesis is not only valid for the case of small deformations, but also it is used in large deformation with an updated Lagrangian formulation.Thus, the Green-Lagrange strain tensor $\mathbf{E}$ and the Piola-Kirchhoff stress tensor $\mathbf{S}$ are noted respectively in this section by $\varepsilon$ and $\sigma$.

The stress tensor is decomposed also into two parts, the first one is spherical $\sigma_{m} \boldsymbol{I}$ and the second is deviatoric, as:

$$
\boldsymbol{\sigma}=\sigma_{m} \boldsymbol{I}+\boldsymbol{S} ; \sigma_{m}=\frac{1}{3} \operatorname{trace}(\boldsymbol{\sigma})
$$

The stress field is related on the elastic strain tensor as:

$$
\dot{\sigma}=\boldsymbol{D}: \dot{\boldsymbol{\varepsilon}}^{e}
$$

where $\boldsymbol{D}$ represents the tangent modulus. In this work, we focus on the Von-Mises $J_{2}$ plastic criterion with isotropic hardening. The plastic surface $f$ is defined in function of the yield and deviatoric stresses $\sigma_{y}$ and $S$ as [46,47]:

$$
f=\sqrt{3 / 2}\|S\|-\sigma_{y} \leq 0
$$

Thus, the plastic strain takes the following form:

$$
\dot{\boldsymbol{\varepsilon}}^{p}=\dot{\gamma} \frac{\partial f}{\partial \boldsymbol{\sigma}}=\sqrt{3 / 2} \dot{\gamma} \boldsymbol{n} ; \boldsymbol{n}=\frac{\boldsymbol{S}}{\|\boldsymbol{S}\|}
$$

Here $\dot{\gamma}$ is the plastic multiplier, which is defined in function of the loading conditions.

\subsection{Numerical resolution}

The considered numerical scheme in this study is the Euler (implicit) approach in which the Eq (13) is integrated as the following expression

$$
\boldsymbol{\varepsilon}_{n+1}^{p}=\boldsymbol{\varepsilon}_{n}^{p}+\sqrt{3 / 2} \Delta \gamma \boldsymbol{n}_{n+1} \quad ; \quad \boldsymbol{n}_{n+1}=\frac{\boldsymbol{S}_{n+1}}{\left\|\boldsymbol{S}_{n+1}\right\|}
$$

The decomposition of the stress tensor Eq (10) and the elasticity relation Eq (11), give:

$$
\begin{aligned}
& \boldsymbol{\sigma}_{n+1}=\boldsymbol{D} \cdot\left(\boldsymbol{\varepsilon}_{n+1}-\boldsymbol{\varepsilon}_{n}^{p}\right) \\
& \boldsymbol{\sigma}_{n+1}=\boldsymbol{\sigma}^{\text {trial }}-2 \mu \sqrt{3 / 2} \Delta \gamma \boldsymbol{n}_{n+1} ; \boldsymbol{S}_{n+1}=\boldsymbol{S}^{\text {trial }}-2 \mu \sqrt{3 / 2} \Delta \gamma \boldsymbol{n}_{n+1}
\end{aligned}
$$


Referring to the Eq (12), the equation to solve takes the following form

$$
f=\sqrt{\frac{3}{2}}\left\|S^{\text {trial }}\right\|-3 \Delta \gamma \mu-\sigma_{y}=0
$$

The resolution of this equation is via the Newton-Raphson method. Considering the consistence condition of the tangent modulus, we obtain

$$
\partial_{\varepsilon} f=\sqrt{\frac{3}{2}} \partial_{\varepsilon}\left\|S^{\text {trial }}\right\|-x_{3} \partial_{\varepsilon}(\Delta \gamma)=0 ; x_{3}=3 \mu+\sigma_{y}^{\prime}
$$

Where

$$
\partial_{\varepsilon}\left\|S^{\text {trial }}\right\|=2 \mu \boldsymbol{n}^{\text {trial }}
$$

And

$$
\partial_{\varepsilon}(\Delta \gamma)=A \boldsymbol{n}^{\text {trial }} ; A=\frac{\sqrt{3 / 2}-2 \mu}{x_{3}}
$$

Thus, the Eq (16) is linearized as the following form

$$
\partial_{\varepsilon} \sigma_{n+1}=\partial_{\varepsilon} \sigma^{\text {trial }}-2 \mu \sqrt{3 / 2}\left(\partial_{\varepsilon}(\Delta \gamma) \boldsymbol{n}_{n+1}+\Delta \gamma \partial_{\varepsilon} \boldsymbol{n}^{\text {trial }}\right)
$$

Finally, the expression of the tangent modulus is

$$
\begin{aligned}
& \partial_{\varepsilon} \boldsymbol{\sigma}_{n+1}=K \boldsymbol{I} \otimes \boldsymbol{I}+2 \mu\left(1-\sqrt{3 / 2} \Delta \gamma \frac{2 \mu}{\left\|\boldsymbol{S}^{\text {trial }}\right\|}\right)\left(\boldsymbol{I}-\frac{1}{3} \boldsymbol{I} \otimes \boldsymbol{I}\right) \\
& +2 \mu \sqrt{3 / 2}\left(\Delta \gamma \frac{2 \mu}{\left\|\boldsymbol{S}^{\text {trial }}\right\|}-A\right) \boldsymbol{n}^{\text {trial }} \otimes \boldsymbol{n}^{\text {trial }}
\end{aligned}
$$

\section{Solid shell finite element formulation}

The derived solid shell element (SS) is an eight nodes hexahedral element with three degree of freedom at each node. The variational principle with enhanced assumed strain (EAS) is applied. The EAS method [8] is used in the enhancement of compatible part of Green-Lagrange stain $\mathbf{E}^{c}$ with an enhanced strain $\tilde{\mathbf{E}}$ to obtain the total Green-Lagrange strain tensor, as following:

$$
\mathbf{E}=\mathbf{E}^{c}+\tilde{\mathbf{E}}
$$

The three field Hu-Washizu (FHW) variational principle is:

$$
\Pi(\mathbf{u}, \tilde{\mathbf{E}}, \mathbf{S})=\int_{V}\left(\psi\left(\mathbf{E}^{c}+\tilde{\mathbf{E}}\right)\right) d V-\int_{V}(\mathbf{S}: \tilde{\mathbf{E}}) d V-\int_{V} \mathbf{F}_{V} \cdot \mathbf{u} d V-\int_{\partial V_{f}} \mathbf{F}_{S} \cdot \mathbf{u} d A
$$

Where $\psi$ is the Helmotz strain energy function. u, $\tilde{\mathbf{E}}, \mathbf{S}$ are the independent tensorial quantities which are respectively the displacement vector, the incompatible strain and the independent part of Piola-Kirchhoff stress tensor, respectively. $\mathbf{F}_{V}$ and $\mathbf{F}_{s}$ are the body and the surface forces.

By introducing the orthogonality condition, one can reduce two independent variables, $\mathbf{u}$ and $\tilde{\mathbf{E}}$

$$
\int_{V} \mathbf{S}: \tilde{\mathbf{E}} d V=0
$$

The weak form of the reduced fields FHW functional obtained by the derivation of $\Pi$ takes the following form: 


$$
G(\mathbf{u}, \tilde{\mathbf{E}})=\int_{V} \mathbf{S}:\left(\delta \mathbf{E}^{c}+\delta \tilde{\mathbf{E}}\right) d V-\int_{V} \mathbf{F}_{V} \cdot \delta \mathbf{u} d V-\int_{\partial V_{f}} \mathbf{F}_{S} \cdot \delta \mathbf{u} d A=0
$$

$\mathbf{S}$ is the second Piola-Kirchhoff stress tensor, is defined as:

$$
\mathbf{S}=\frac{\partial \psi}{\partial \mathbf{E}}
$$

\subsection{Finite element approximations}

The position vectors $\mathbf{X}$ and $\mathbf{x}$ relative respectively to reference and current configurations are expressed using the curvilinear coordinates as:

$$
\mathbf{X}=\sum_{I=1}^{8} \mathrm{~N}_{I}(\xi, \eta, \zeta) \cdot \mathbf{X}_{I} ; \quad \mathbf{x}=\sum_{I=1}^{8} \mathrm{~N}_{I}(\xi, \eta, \zeta) \cdot \mathbf{x}_{I}
$$

Where $\mathbf{X}_{I}$ and $\mathbf{x}_{I}$ are the nodal coordinates, $\mathrm{N}_{I}$ are the isoparametric shape functions:

$$
\mathrm{N}_{I}=\frac{1}{8}\left(1+\xi_{i} \cdot \xi\right) \cdot\left(1+\eta_{i} \eta\right) \cdot\left(1+\eta_{i} \eta\right)
$$

In the same manner, the displacement vector, its variation and increment are respectively interpolated as:

$$
\mathbf{u}=\sum_{I=1}^{n} \mathrm{~N}_{I} \cdot \mathbf{U}_{I} \quad ; \quad \delta \mathbf{u}=\sum_{I=1}^{n} \mathrm{~N}_{I} \cdot \delta \mathbf{U}_{I} \quad ; \quad \Delta \mathbf{u}=\sum_{i=1}^{n} \mathrm{~N}_{I} \cdot \Delta \mathbf{U}_{I}
$$

$\mathbf{U}_{I}=\left[\mathbf{u}_{1}^{T}, \mathbf{u}_{2}^{T}, \ldots, \mathbf{u}_{8}^{T}\right]=\left[u_{1}, v_{1}, w_{1}, u_{2}, v_{2}, w_{2}, \ldots, u_{8}, v_{8}, w_{8}\right]^{T}$ is the nodal displacement vector in the element level.

\subsection{ANS method}

The compatible Green-Lagrange strain tensor is written in the vectoriel following form:

$$
\mathbf{E}^{c}=\left[E_{11}^{c}, E_{22}^{c}, E_{33}^{c}, 2 E_{12}^{c}, 2 E_{13}^{c}, 2 E_{23}^{c}\right]^{T}
$$

where

$$
E_{i j}=\frac{1}{2}\left(g_{i j}-G_{i j}\right)
$$

$G_{i j}=\mathbf{G}_{i} \cdot \mathbf{G}_{j}$ and $g_{i j}=\mathbf{g}_{i} \cdot \mathbf{g}_{j}$ are respectively the metric coefficients of reference and current configurations. $\mathbf{G}_{i}$ and $\mathbf{g}_{i}$ are respectively the covariant base vectors in the initial and deformed configurations, are the position vector derivations with the parametric vectors.

In order to avoid transverse shear locking, the transverse shear strains, $E_{13}^{c}, E_{23}^{c}$ are modified according to the ANS method [7]:

$$
\left[\begin{array}{c}
2 E_{13}^{c} \\
2 E_{23}^{c}
\end{array}\right]=F(z)\left[\begin{array}{c}
(1-\eta) E_{13}^{B}+(1+\eta) E_{13}^{D} \\
(1-\xi) E_{23}^{A}+(1+\xi) E_{23}^{C}
\end{array}\right]
$$

Where $F(\mathrm{z})$ is the parabolic distribution of the modified FSDT [29].

$$
F(z)=\frac{5}{4}\left(1-4\left(\frac{z}{h}\right)^{2}\right)
$$


As depicted in figure 1 , A $(-1,0,0), \mathrm{B}(0,-1,0), \mathrm{C}(1,0,0), \mathrm{D}(0,1,0)$, are the interpolation points computed in the mid-surface of the hexahedral element $(\zeta=0)$.

The transverse strain $E_{33}^{c}$ is modified as represent the following expression:

$$
E_{33}^{c}=\sum_{L=1}^{4} \frac{1}{4}\left(1+\xi_{L} \xi\right)\left(1+\eta_{L} \eta\right) E_{33}^{L}
$$

$L=\mathrm{A}_{1}(-1,-1,0), \mathrm{A}_{2}(1,-1,0), \mathrm{A}_{3}(1,1,0), \mathrm{A}_{4}(-1,1,0)$ are the four interpolation points as presented in figure 1 .

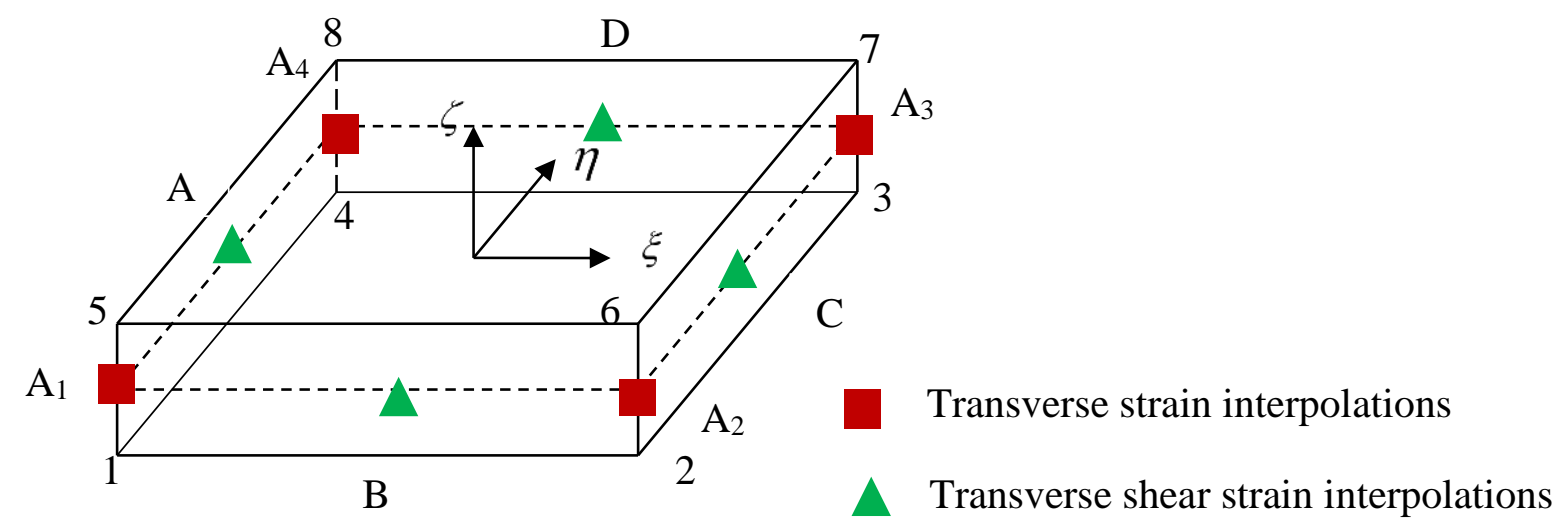

Figure 1. Transverse shear and transverse strain interpolations

Then using finite element approximations, the compatible stain tensor, its variation and increment are interpolated as:

$$
\boldsymbol{E}^{c}=\boldsymbol{B} \boldsymbol{U}_{e} ; \delta \boldsymbol{E}^{c}=\boldsymbol{B} \delta \boldsymbol{U}_{e} ; \Delta \boldsymbol{E}^{c}=\boldsymbol{B} \Delta \boldsymbol{U}_{e}
$$

Where $\boldsymbol{U}_{e}$ is the nodal displacement vector and $\boldsymbol{B}$ is the compatible strain interpolation matrix, expressed in the nodal level as follows:

$$
\boldsymbol{B}_{I}=\boldsymbol{T}_{s}^{-T}\left[\begin{array}{c}
\boldsymbol{g}_{1}^{T} N_{I, 1} \\
\boldsymbol{g}_{1}^{T} N_{I, 1} \\
\sum_{A=1}^{4} \frac{1}{4}\left(1+\xi_{A} \xi\right)\left(1+\eta_{A} \eta\right) \boldsymbol{g}_{3}^{T} N_{I, 3} \\
\boldsymbol{g}_{2}^{T} N_{I, 1}+\boldsymbol{g}_{1}^{T} N_{I, 2} \\
\frac{1}{2}\left[(1-\eta)\left(\boldsymbol{g}_{3}^{B^{T}} N_{I, 1}^{B}+\boldsymbol{g}_{1}^{B^{T}} N_{I, 3}^{B}\right)+(1+\eta)\left(\boldsymbol{g}_{3}^{D^{T}} N_{I, 1}^{D}+\boldsymbol{g}_{1}^{D^{T}} N_{I, 3}^{D}\right)\right] \\
\frac{1}{2}\left[(1-\xi)\left(\boldsymbol{g}_{3}^{A^{T}} N_{I, 1}^{A}+\boldsymbol{g}_{1}^{A^{T}} N_{I, 3}^{A}\right)+(1+\xi)\left(\boldsymbol{g}_{3}^{C^{T}} N_{I, 1}^{C}+\boldsymbol{g}_{1}^{C^{T}} N_{I, 3}^{C}\right)\right.
\end{array}\right]
$$

$\boldsymbol{T}_{s}$ is the strain transformation matrix from parametric to cartesian coordinates, written in the following form: 


$$
\boldsymbol{T}_{s}=\left[\begin{array}{cccccc}
\left(t_{11}\right)^{2} & \left(t_{21}\right)^{2} & \left(t_{31}\right)^{2} & 2 t_{11} t_{21} & 2 t_{11} t_{31} & 2 t_{21} t_{31} \\
\left(t_{12}\right)^{2} & \left(t_{22}\right)^{2} & \left(t_{32}\right)^{2} & 2 t_{12} t_{22} & 2 t_{12} t_{32} & 2 t_{22} t_{32} \\
\left(t_{13}\right)^{2} & \left(t_{23}\right)^{2} & \left(t_{33}\right)^{2} & 2 t_{13} t_{23} & 2 t_{13} t_{33} & 2 t_{23} t_{33} \\
t_{11} t_{12} & t_{21} t_{22} & t_{31} t_{32} & t_{11} t_{22}+t_{12} t_{21} & t_{11} t_{32}+t_{12} t_{31} & t_{21} t_{32}+t_{22} t_{31} \\
t_{11} t_{13} & t_{21} t_{23} & t_{31} t_{33} & t_{11} t_{23}+t_{13} t_{21} & t_{11} t_{33}+t_{13} t_{31} & t_{21} t_{33}+t_{23} t_{31} \\
t_{12} t_{13} & t_{22} t_{23} & t_{32} t_{33} & t_{12} t_{23}+t_{13} t_{22} & t_{12} t_{33}+t_{13} t_{32} & t_{22} t_{33}+t_{23} t_{32}
\end{array}\right]
$$

In which $t_{i j}=\mathbf{G}_{i} \cdot \boldsymbol{T}_{j}$ and $\boldsymbol{T}_{i}(i=1,2,3)$ are the vectors of local orthonormal base.

\subsection{EAS method}

The enhanced strain [8] is expressed in function of the independent parameters vector $\boldsymbol{\alpha}$ as :

$$
\tilde{\mathbf{E}}=\tilde{\mathbf{M}}(\xi, \eta, \zeta) \boldsymbol{\alpha} ; \delta \tilde{\mathbf{E}}=\tilde{\mathbf{M}}(\xi, \eta, \zeta) \delta \boldsymbol{\alpha} ; \Delta \tilde{\mathbf{E}}=\tilde{\mathbf{M}}(\xi, \eta, \zeta) \Delta \boldsymbol{\alpha}
$$

Where

$$
\tilde{\mathbf{M}}(\xi, \eta, \zeta)=\frac{\operatorname{det} \mathbf{J}_{0}}{\operatorname{det} \mathbf{J}}\left(\mathbf{T}_{S}^{0}\right)^{-T} \mathbf{M}(\xi, \eta, \zeta)
$$

$\mathbf{J}=\left[\boldsymbol{G}_{1}, \boldsymbol{G}_{2}, \boldsymbol{G}_{3}\right]$ is the Jacobian matrix, $\mathbf{J}_{0}$ and $\mathbf{T}_{S}^{0}$ are the Jacobian and the transformation matrices at the element center.

According to the orthogonality condition (eq 25), the interpolation matrix $\mathbf{M}(\xi, \eta, \zeta)$ can be written in the following form:

$$
\begin{aligned}
\mathbf{M}^{5} & =\left(\begin{array}{lllll}
\xi & 0 & 0 & 0 & 0 \\
0 & \eta & 0 & 0 & 0 \\
0 & 0 & \zeta & 0 & 0 \\
0 & 0 & 0 & \xi & \eta \\
0 & 0 & 0 & 0 & 0 \\
0 & 0 & 0 & 0 & 0
\end{array}\right) \\
\mathbf{M}^{7} & =\left(\begin{array}{llllllc}
\xi & 0 & 0 & 0 & 0 & 0 & 0 \\
0 & \eta & 0 & 0 & 0 & 0 & 0 \\
0 & 0 & \zeta & 0 & 0 & \xi \zeta & \eta \zeta \\
0 & 0 & 0 & \xi & \eta & 0 & 0 \\
0 & 0 & 0 & 0 & 0 & 0 & 0 \\
0 & 0 & 0 & 0 & 0 & 0 & 0
\end{array}\right) \\
\mathbf{M}^{9} & =\left(\begin{array}{lllllcccc}
\xi & 0 & 0 & 0 & 0 & 0 & 0 & \xi \eta & 0 \\
0 & \eta & 0 & 0 & 0 & 0 & 0 & 0 & \xi \eta \\
0 & 0 & \zeta & 0 & 0 & \xi \zeta & \eta \zeta & 0 & 0 \\
0 & 0 & 0 & \xi & \eta & 0 & 0 & 0 & 0 \\
0 & 0 & 0 & 0 & 0 & 0 & 0 & 0 & 0 \\
0 & 0 & 0 & 0 & 0 & 0 & 0 & 0 & 0
\end{array}\right)
\end{aligned}
$$


$\mathbf{M}^{5}, \mathbf{M}^{7}, \mathbf{M}^{9}$ are the interpolation matrices with respectively 5,7 and 9 parameters.

\subsection{Weak form linearization}

The weak form $G$ presents nonlinear terms. For that reason, the Newton Raphson method is applied for the linearization of equation (26), as follows:

$$
G+D G .(\Delta \mathbf{u}, \Delta \boldsymbol{\alpha})=\left\langle\delta \mathbf{U}_{e} \quad \delta \boldsymbol{\alpha}\right\rangle\left(\left[\begin{array}{cc}
\mathbf{K} & \mathbf{L}^{T} \\
\mathbf{L} & \mathbf{H}
\end{array}\right]\left\{\begin{array}{c}
\Delta \mathbf{U}_{e} \\
\Delta \boldsymbol{\alpha}
\end{array}\right\}-\left[\begin{array}{c}
\mathbf{f}^{e x t}-\mathbf{f}^{i n t} \\
-\mathbf{h}
\end{array}\right]\right)
$$

Where $\mathbf{h}, \mathbf{f}^{\text {int }}$ and $\mathbf{f}^{\text {ext }}$ are given by:

$$
\mathbf{h}=\int_{V_{e}} \tilde{\mathbf{M}}^{T} \mathbf{S} d V_{e} ; \mathbf{f}^{\text {int }}=\int_{V_{e}} \mathbf{B}^{T} \mathbf{S} d V_{e} ; \mathbf{f}^{e x t}=\int_{V_{e}} \mathbf{N}^{T} \mathbf{F}_{V} d V_{e}+\int_{\partial V_{f e}} \mathbf{N}^{T} \mathbf{F}_{S} d A
$$

$\mathbf{K}, \mathbf{L}$ and $\mathbf{H}$ are expressed as following:

$$
\mathbf{K}=\mathbf{K}_{D}+\mathbf{K}_{G} ; \mathbf{L}=\int_{V_{e}} \tilde{\mathbf{M}}^{T} \mathbf{D B} d V_{e} ; \mathbf{H}=\int_{V_{e}} \tilde{\mathbf{M}}^{T} \mathbf{D} \tilde{\mathbf{M}} d V_{e}
$$

Where $\boldsymbol{D}=\frac{\partial \mathbf{S}}{\partial \mathbf{E}}$ is the material tangent moduli. $\mathbf{K}_{D}$ is the material stiffness tensor, defined:

$$
\mathbf{K}_{D}=\int_{V_{e}} \mathbf{B}^{T} \mathbf{D B} d V_{e}
$$

and $\mathbf{K}_{G}$ is the geometric stiffness matrix, relative to (I, J) nodes couple:

$$
\begin{aligned}
& \mathbf{K}_{G}^{I J}=\int_{V} \operatorname{diag}\left[\begin{array}{lll}
G_{I J} & G_{I J} & G_{I J}
\end{array}\right] d V \\
& G_{I J}=\mathbf{S}^{T} \mathbf{T}_{s}^{-T}\left[\begin{array}{c}
\mathrm{N}_{I, 1} \mathrm{~N}_{J, 1} \\
\mathrm{~N}_{I, 2} \mathrm{~N}_{J, 2} \\
\sum_{L=1}^{4} \frac{1}{4}(1+\xi \xi)\left(1+\eta_{L} \eta\right) \mathrm{N}_{I, 3}^{L} \mathrm{~N}_{J, 3}^{L} \\
\mathrm{~N}_{I, 1} \mathrm{~N}_{J, 2}+\mathrm{N}_{I, 2} \mathrm{~N}_{J, 1} \\
\frac{1}{2}\left[(1-\eta)\left(\mathrm{N}_{I, 1}^{B} \mathrm{~N}_{J, 3}^{B}+\mathrm{N}_{I, 3}^{B} \mathrm{~N}_{J, 1}^{B}\right)+(1+\eta)\left(\mathrm{N}_{I, 1}^{D} \mathrm{~N}_{J, 3}^{D}+\mathrm{N}_{I, 3}^{D} \mathrm{~N}_{J, 1}^{D}\right)\right] \\
\frac{1}{2}\left[(1-\xi)\left(\mathrm{N}_{I, 2}^{A} \mathrm{~N}_{J, 3}^{A}+\mathrm{N}_{I, 3}^{A} \mathrm{~N}_{J, 2}^{A}\right)+(1+\xi)\left(\mathrm{N}_{I, 2}^{C} \mathrm{~N}_{J, 3}^{C}+\mathrm{N}_{I, 3}^{C} \mathrm{~N}_{J, 2}^{C}\right)\right]
\end{array}\right]
\end{aligned}
$$

Then, applying the static condensation procedure, the strain parameters vector $\Delta \boldsymbol{\alpha}$ is given by:

$$
\Delta \boldsymbol{\alpha}=-\mathbf{H}^{-1}\left(\mathbf{h}+\mathbf{L} \Delta \mathbf{U}_{e}\right)
$$

The stiffness matrix and the residual vector are expressed at the element level as following:

$$
\mathbf{K}_{e}=\mathbf{K}-\mathbf{L}^{T} \mathbf{H}^{-1} \mathbf{L} ; \mathbf{R}_{e}=\mathbf{L}^{T} \mathbf{H}^{-1} \mathbf{h}+\mathbf{f}^{e x t}-\mathbf{f}^{\text {int }}
$$

\section{Numerical results}

In this part, numerical simulations are carried out in order to assess the robustness and the performance of the solid shell finite element. The SS element was implemented into the user element (UEL) interface via FOTRAN user subroutines. Various benchmark linear and nonlinear tests are presented in section 5.1 using isotopic standard material and FGM. In section 5.2, we consider the analysis of FG shells under low velocity impact. Simulations of the contact 
problem are performed adopting a single element in the thickness direction. Table 1 describes the different finite elements applied in this section.

Table 1. Description of different finite element

\begin{tabular}{ll}
\hline Element & Description \\
\hline C3D8 & Hexahedral solid element of ABAQUS \\
C3D8I & Incompatible hexahedral solid element of ABAQUS \\
SS5 & Solid shell element enhanced with 5 incompatible modes \\
SS7 & Solid shell element enhanced with 7 incompatible modes \\
SS9 & Solid shell element enhanced with 9 incompatible modes \\
\hline
\end{tabular}

\subsection{Solid shell element validation}

\subsubsection{Distorted plate test}

The purpose of this benchmark problem is to demonstrate the robustness of solid shell element and to validate the linear static formulation implemented in ABAQUS. This test consists of a square clamped plate subjected to a concentrated load F (figure 2). The geometric properties, described in figure 3, are proposed by Klinkel [48]. The plate material behavior is considered elastic with the following properties: $E=10^{4} \mathrm{MPa}$ and $v=0.3$. Considering the symmetry of problem, only one quarter of the plate is discretized by $2 \times 2$ elements.

The objective of this test is to predict the evolution of displacement in function of the element distortion. The obtained numerical result are compared to the analytical displacement derived by Timoshenko and Woinosky-Krieger [49] as:

$$
W_{\text {exact }}=0.0056 F L^{2} \frac{12\left(1-v^{2}\right)}{E h^{3}}=1 \mathrm{~mm}
$$

One can notice that the solid shell result is well correlated with the analytical result. This can be explained by the fact that the ANS method avoids transverse shear locking.

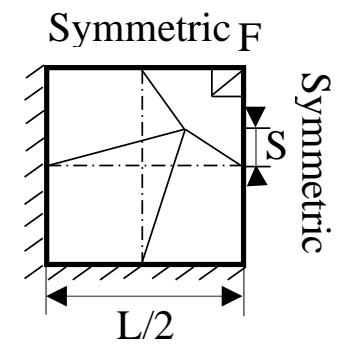

$$
\begin{aligned}
& \mathrm{L}=100 \mathrm{~mm} \\
& \mathrm{~h}=1 \mathrm{~mm} \\
& E=10^{4} \mathrm{MPa} \\
& v=0.3
\end{aligned}
$$

Figure 2. Description of the distorted plate test with hexahedral elements 


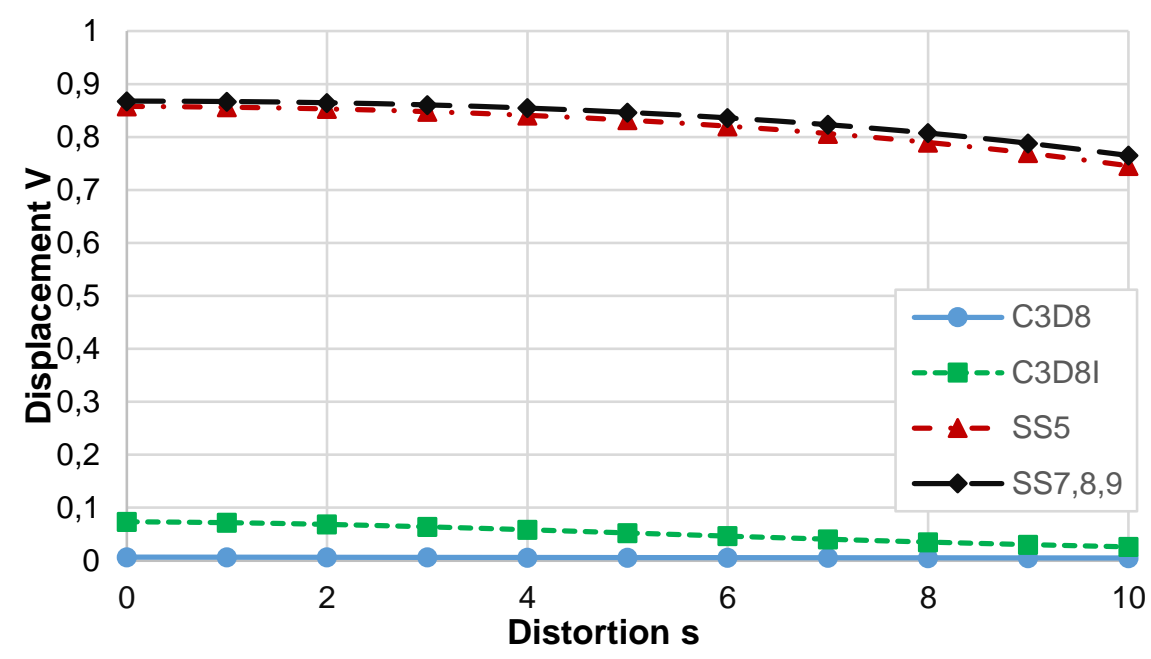

Figure 3. Plate deflection in function of distortion

\subsubsection{Dynamic test of a spherical cap under a concentrated load}

In this section, we consider the test of spherical cap in order to demonstrate the solid shell element performance under dynamic problems. It consists on a spherical shell clamped and subjected in the center to a concentrated force. $F=100$ [50]. The geometrical and material properties are the following: $R=4.76, h=0.01576, \theta=10.9^{\circ}, \rho=0.000245$. Owning to the shell symmetry, only one quarter of the problem is studied (figure 4 ).
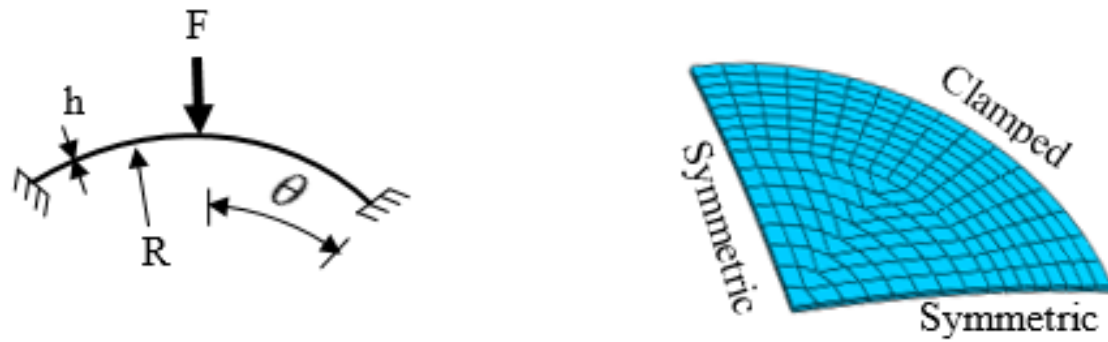

Figure 4. Description of spherical cap test

The time increment is fixed to $\Delta \mathrm{t}=0.2 \mu \mathrm{s}$. The dynamic responses of the deflection for the linear and nonlinear case are shown in Figures 5 and 6. Results are compared with ABAQUS solid finite elements and numerical results of Duarte Filho and Awruch [50]. All results show a good correlation except for C3D8 which require further discretization and more element for accurate solution. 


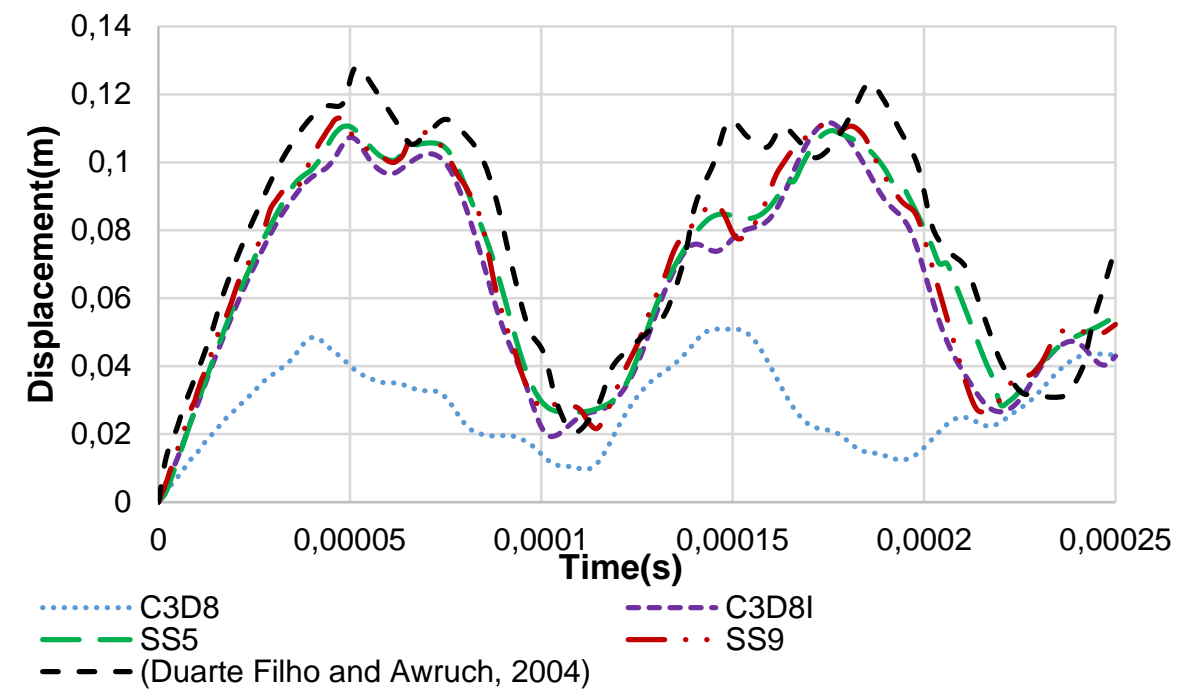

Figure 5. Dynamic and linear response of the spherical cap

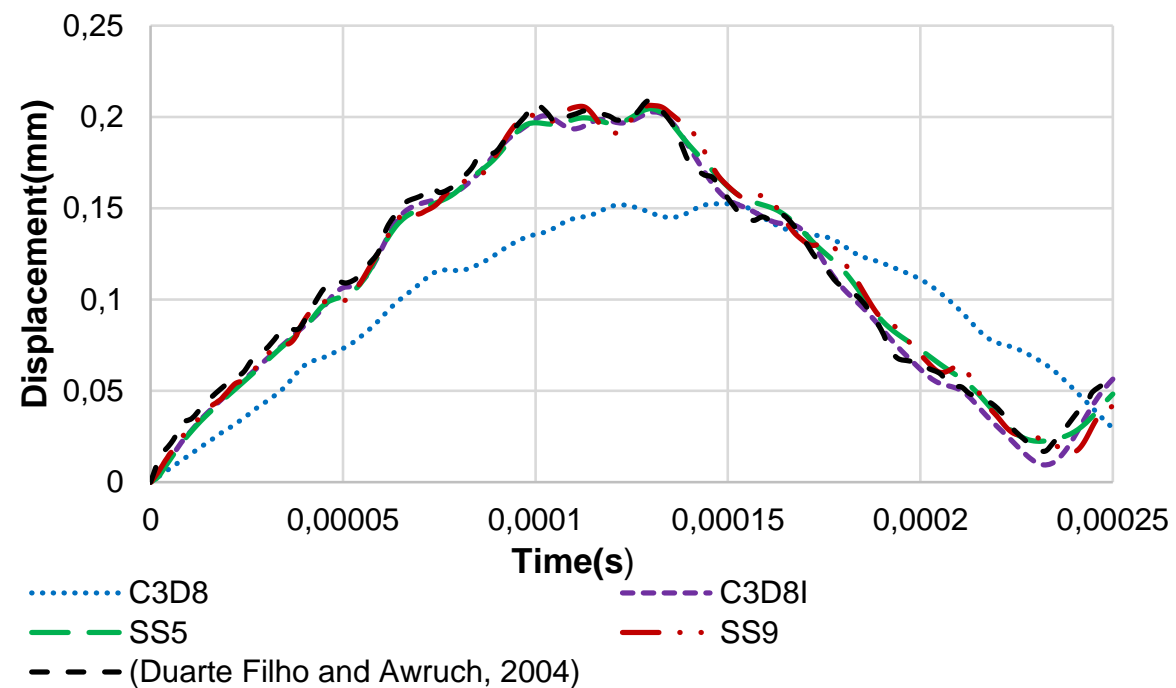

Figure 6. Dynamic and nonlinear response of the spherical cap

\subsubsection{Pulled cylinder test}

The pulled cylinder test consists on short cylinder subjected at the middle to two pinching forces F. The geometrical properties are defined by the cylinder radius $R=4.953$, the length $L=10.35$ and the thickness $\mathrm{h}=0.094$, as illustrated in figure 7 . The concentrated load $F_{\max }=510^{6}$ is subjected to the point A. The FGM is considered with elastic behavior and the material properties of metal are $E_{m}=0.7 \times 10^{9}, v_{m}=0.3$. While, the ceramic properties are $E_{c}=1.51 \times 10^{9}, v_{c}=0.3$. Owning to the cylinder symmetry, only one eight of this problem is studied. The present test was widely treated by $[18,24,48,49]$ 

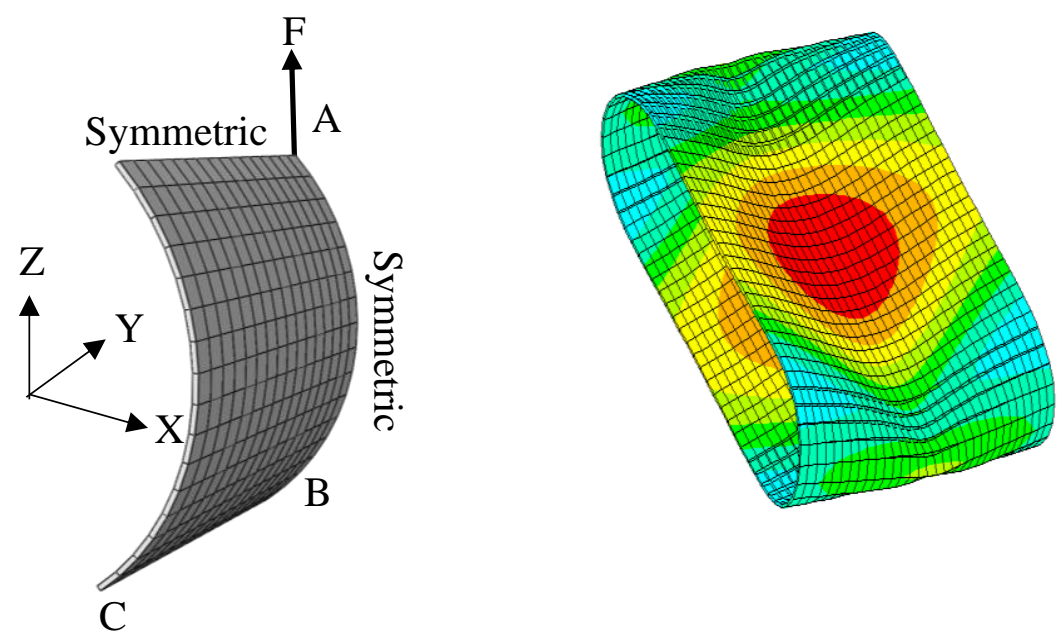

Figure 7. Initial and deformed configuration of the metallic cylinder

The obtained results, the cylinder deflection with different power law index at different point A, B and C are presented in the figures 8, 9 and 10. For all simulations, the used mesh is $16 \times 16$ with a single element solid shell element with five EAS (SS5) parameters and ten gauss integration points through the thickness direction. These results are well correlated with those of Mars et al [18]. In this reference the mixture law was applied to predict the elastic properties. However, Mori-Tanaka model is adopted in the present work, which can explain the small difference between the present results and those obtained by Mars et al [18].

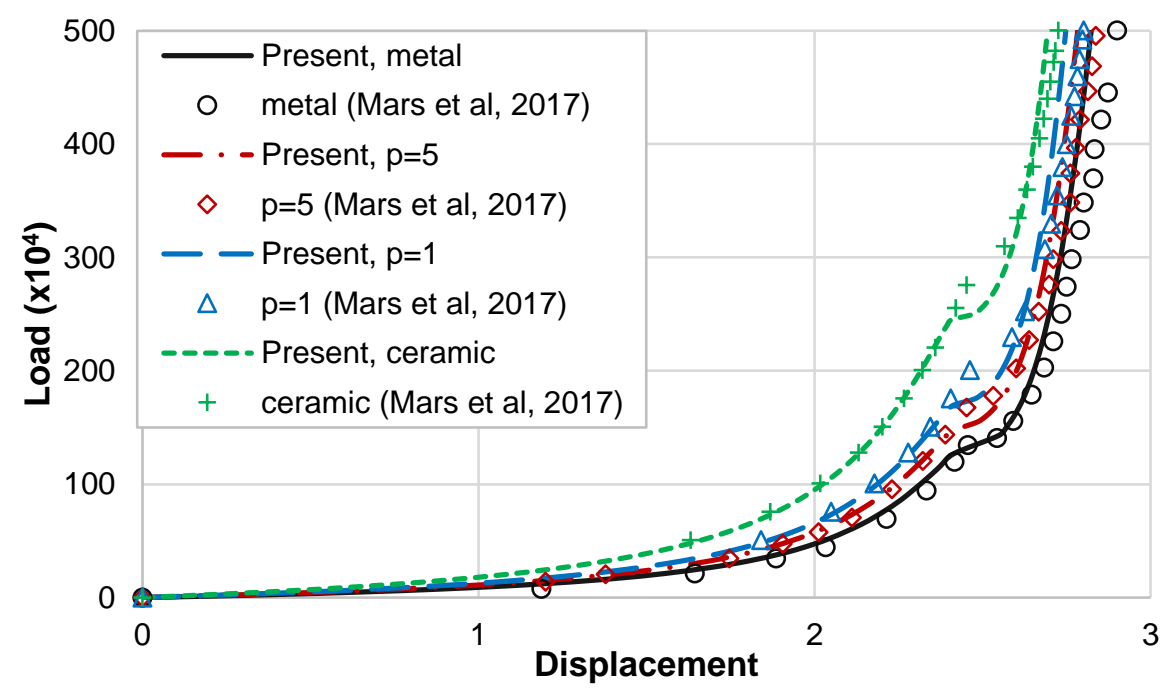

Figure 8. Cylinder deflection at point $A\left(W_{A}\right)$ 


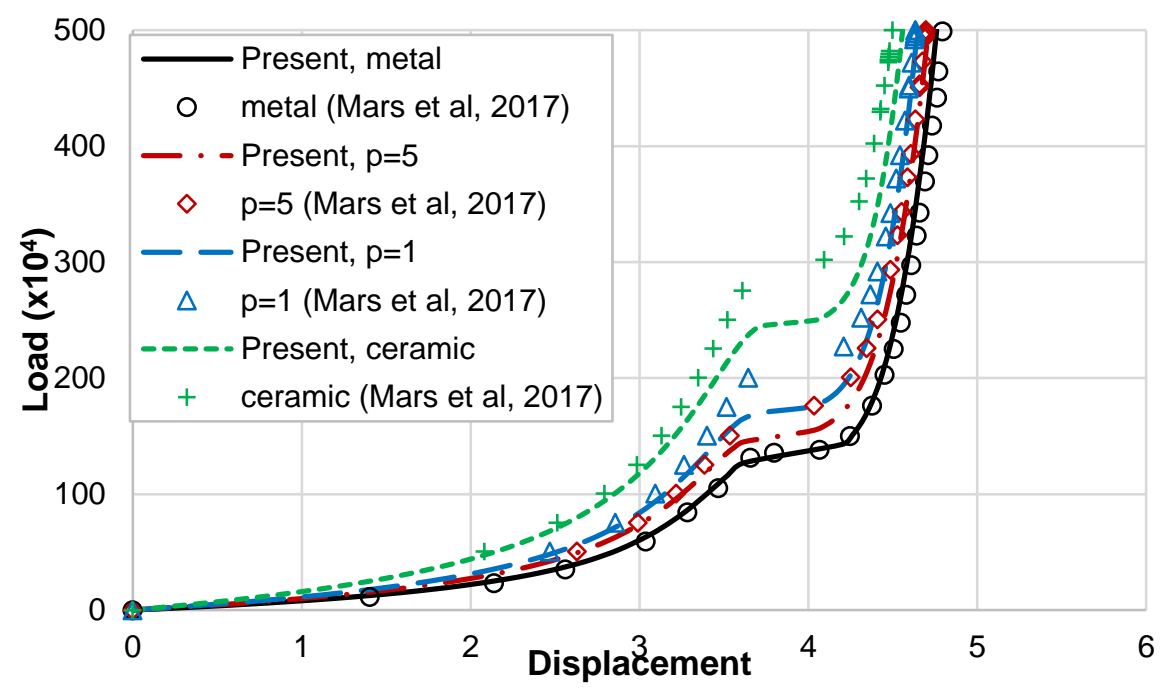

Figure 9.Cylinder deflection at point $B\left(-U_{B}\right)$

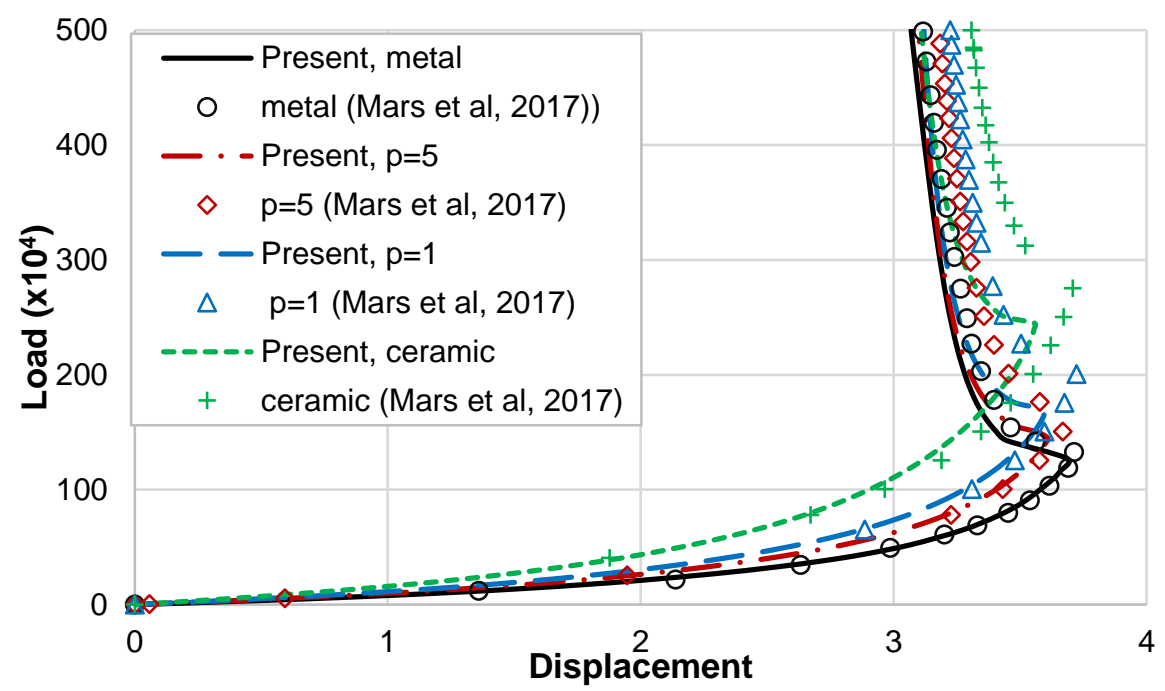

Figure 10. Cylinder deflection at point $C\left(-U_{C}\right)$

\subsection{Numerical results of low velocity impact}

The aim of this section is to apply the developed solid shell element to simulate using ABAQUS/Standard the low velocity impact problem. Two tests are carried out: the objective of the first one is to apply the impact problem on aluminum circular plates and to compare the obtained results with the experimental works of Chen [53] In the second test, the validated model is applied to predict the low velocity impact responses on AL/SiC FGM circular plate.

\subsubsection{Validation of low velocity impact finite element model}

The model of low velocity impact is composed of an aluminum clamped circular plate impacted by a cylindrical projectile with hemispherical nose. The circular plate has a radius $\mathrm{R}=60 \mathrm{~mm}$ and thickness $\mathrm{h}=1 \mathrm{~mm}$. This plate is meshed with 4888 solid shell elements with five EAS parameters SS5. Only one element is applied along the thickness direction and the mesh is refined along the contact zone. The impactor is considered rigid body with radius $R_{p}=6.35 \mathrm{~mm}$ and mass $m_{p}=54.4 \mathrm{~g}$. This impactor is subjected to an initial velocity $\mathrm{V}_{0}=29.9 \mathrm{~m} / \mathrm{s}$. The contact between the aluminum circular plate and the projectile is considered 'node to surface contact'. Due to the symmetric of the impact model, only one quarter of this model is considered (see 
Figure 11). The aluminum behavior is assumed elastic perfectly plastic with the following material properties: $E=69 G P a, v=0.3, \sigma_{y}=290 M P a$ and $\rho=2600 \mathrm{~kg} / \mathrm{m}^{3}$.

The main objective of this test is to determine the temporal responses of the history output contact force. The obtained results are compared with experimental and numerical data of Chen [53], as illustrated in Figure 12.

To improve the robustness and the efficiency of our model, two tests are carried out. In the first one, five hexahedral solid element C3D8 of ABAQUS were applied along the thickness direction to mesh the impact circular plate. While, in the second test, only one solid shell element SS5 was applied in the thickness direction. The aim of these simulations is to compare the CPU time and to compare the contact force response of both models (see Figure 12). The obtained CPU time are depicted in Table 2. We can conclude that the developed solid shell element allows to save more than 10 times of computational time.

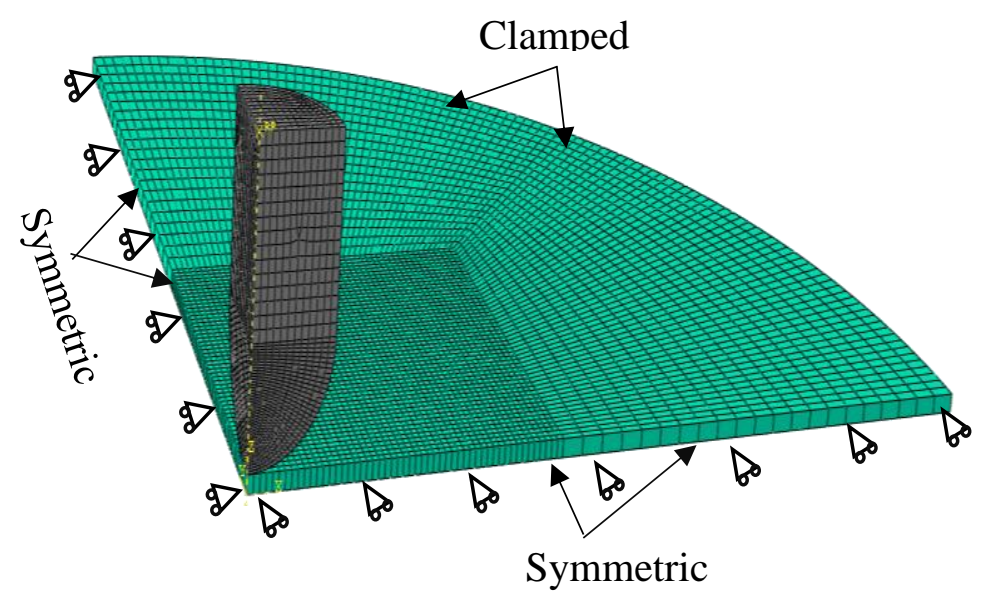

Figure 11. 3D finite element model of low velocity impact

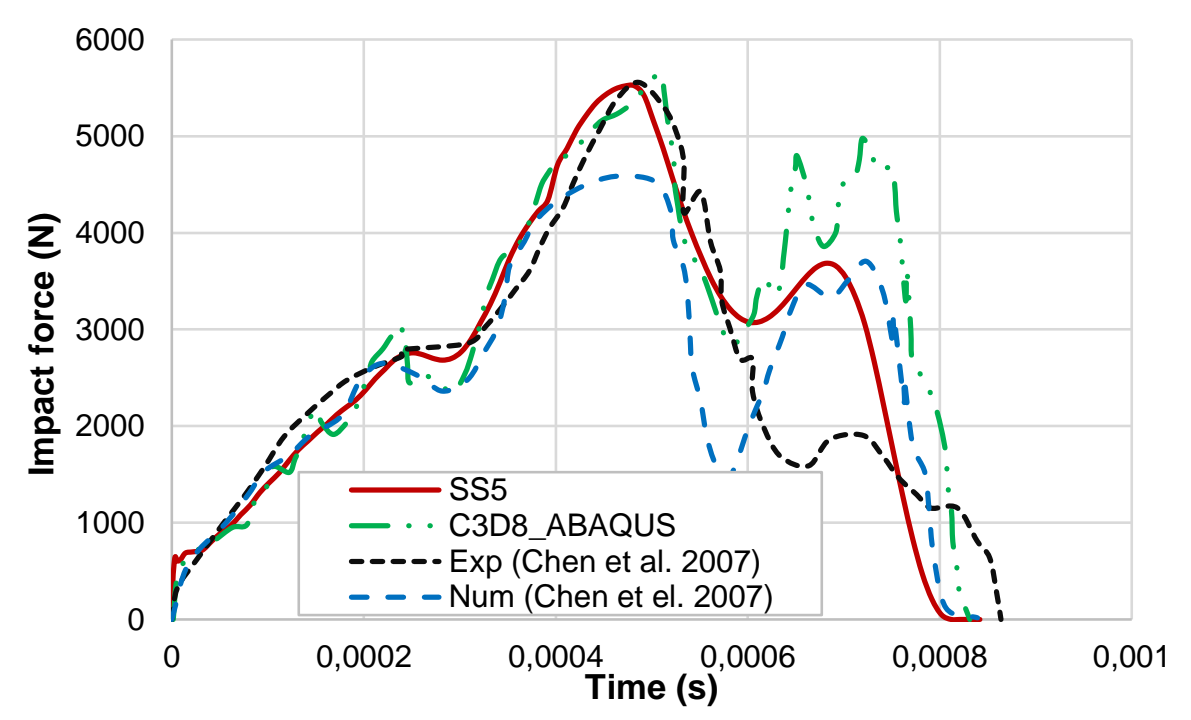

Figure 12. Temporal contact force of aluminum low velocity impact $\left(V_{0}=29.9 \mathrm{~m} / \mathrm{s}\right)$ 
Table 2. CPU time when applying solid shell element and solid element

\begin{tabular}{lll} 
& C3D8 & SS5 \\
\hline CPU time(min) & 407.47 & 36.295 \\
\hline
\end{tabular}

\subsubsection{Low velocity impact on FGM circular plates}

The matrix is on aluminum with elastoplastic behavior. While, the ceramic $\mathrm{SiC}$ is assumed elastic. The volume fraction of this ceramic varies along the thickness direction from $0 \%$ to $70 \%$ when the $\mathrm{z}$ varies respectively from $-\mathrm{h} / 2$ to $\mathrm{h} / 2$. This volume fraction is expressed as a function of the power law index as

$$
V_{c}(z)=0.7\left[1-(0.5-(z / h))^{p}\right]
$$

The matrix and ceramic material properties and elastoplastic parameters are illustrated in Table 3.

Table 4. AL and SiC material properties and elastoplastic parameters [44]

\begin{tabular}{lllllll}
\hline \multicolumn{1}{c}{$\begin{array}{l}\text { Young } \\
\text { modulus } \\
E(G P a)\end{array}$} & $\begin{array}{l}\text { Poisson's } \\
\text { ratio } v\end{array}$ & $\begin{array}{l}\text { Density } \\
\rho\left(\mathrm{kg} / \mathrm{m}^{3}\right)\end{array}$ & $\begin{array}{l}\text { Yield } \\
\text { stress } \\
\sigma_{y}(\mathrm{GPa})\end{array}$ & $\mathrm{k}$ & $n$ \\
\hline $\mathrm{AL} 6061$ & 67 & 0.33 & 2702 & $80.10^{-3}$ & 237.33 & 0.3878 \\
\hline $\mathrm{SiC}$ & 302 & 0.17 & 3100 & - & - & - \\
\hline
\end{tabular}

Low velocity impact simulations are carried out via ABAQUS/Standard to predict the impact solicitations to $\mathrm{Al} / \mathrm{SiC}$ clamped circular plates. we consider the mass of the impactor $\mathrm{m}_{\mathrm{p}}=5.54 \mathrm{Kg}$ subjected to three values of initial velocities $\mathrm{V}_{0}=1 \mathrm{~m} / \mathrm{s}, 2 \mathrm{~m} / \mathrm{s}$ and $3 \mathrm{~m} / \mathrm{s}$. To predict the effect of the power law index of the FGM circular plate, three values are considered 0.1, 1.0 and 10.0. The aim of this simulations is to determine the temporal contact force responses as a function of the power law index (see Figures 13, 14 and 15).

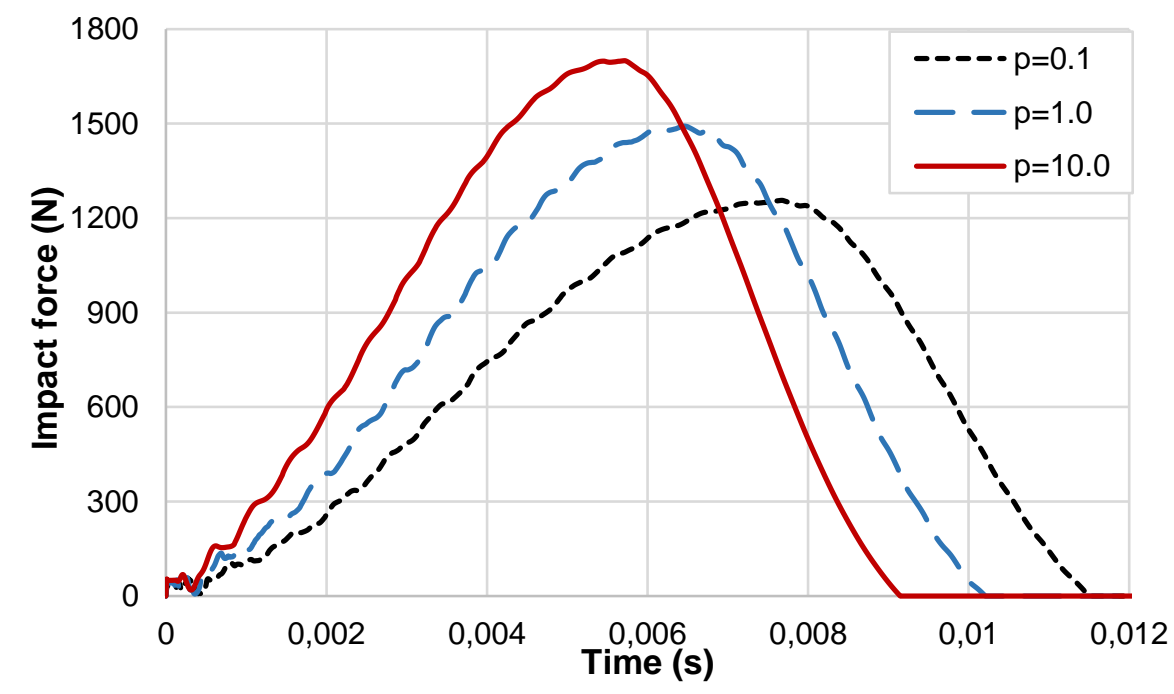

Figure 13. Contact force response of $F G M$ low velocity impact $\left(V_{0}=1 \mathrm{~m} / \mathrm{s}\right)$ 
One can notice that for all values of power lax index the maximum contact force and impact time increase as a function of the impact initial velocity. For the case of $V_{0}=2 \mathrm{~m} / \mathrm{s}$, the plate displacement, the impactor velocity and the kinetic energy of the FGM circular plate applying different power law index are respectively depicted in Figures 16, 17.and 18. We can conclude that the increasing the power law index causes the increase of impactor velocity and the plate kinetic energy and the decrease of plate deflection.

To predict the impactor initial velocity on the impact response, the history contact force curves are illustrated in Figure 19 adopting three values of velocities $V_{0}=1 \mathrm{~m} / \mathrm{s}, 2 \mathrm{~m} / \mathrm{s}$ and $3 \mathrm{~m} / \mathrm{s}$ and fixing $p$ to 10.0. It can be conclude that for a constant value of power law index, the increase of impactor initial velocity generates the increase of maximum contact force value and the decrease of the impact time.

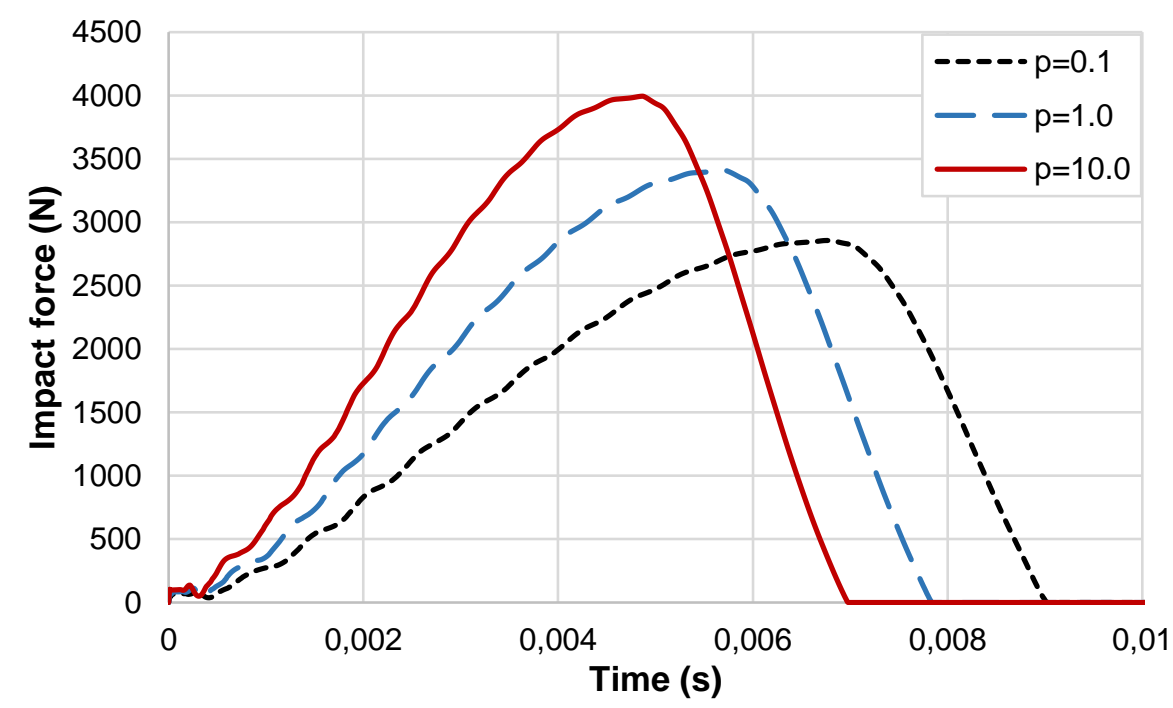

Figure 14. Contact force response of FGM low velocity impact $\left(V_{0}=2 \mathrm{~m} / \mathrm{s}\right)$

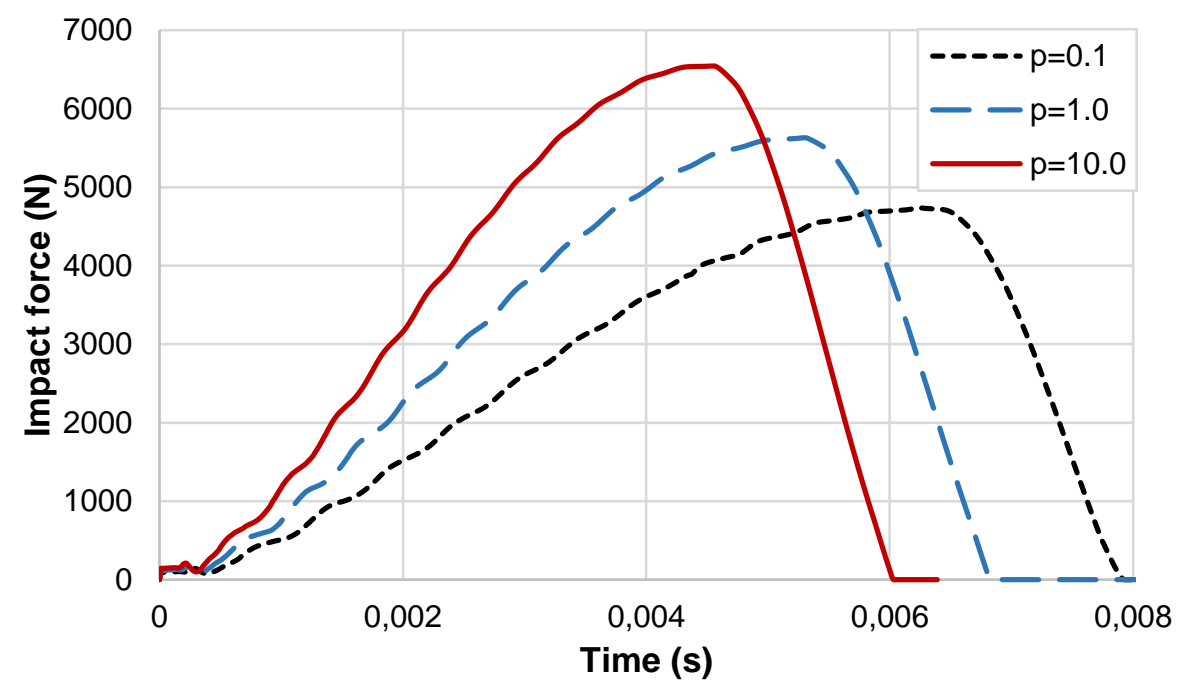

Figure 15. Contact force response of FGM low velocity impact $\left(V_{0}=3 \mathrm{~m} / \mathrm{s}\right)$ 


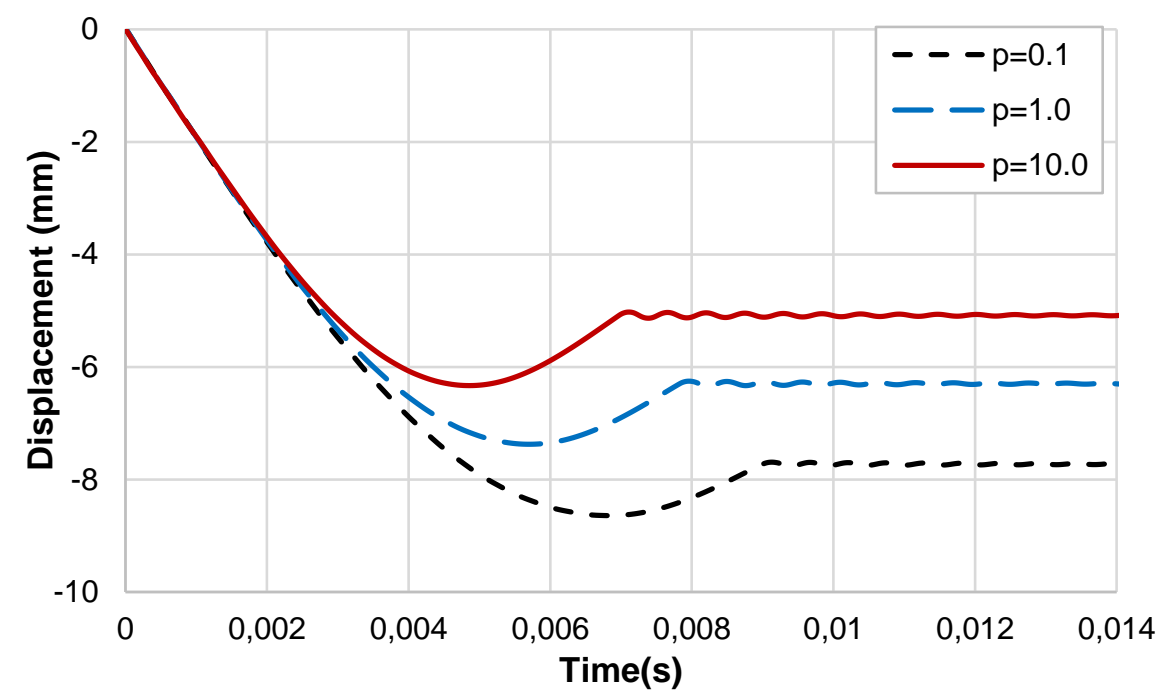

Figure 16. Temporal displacement responses for different power law index $\left(V_{0}=2 \mathrm{~m} / \mathrm{s}\right)$

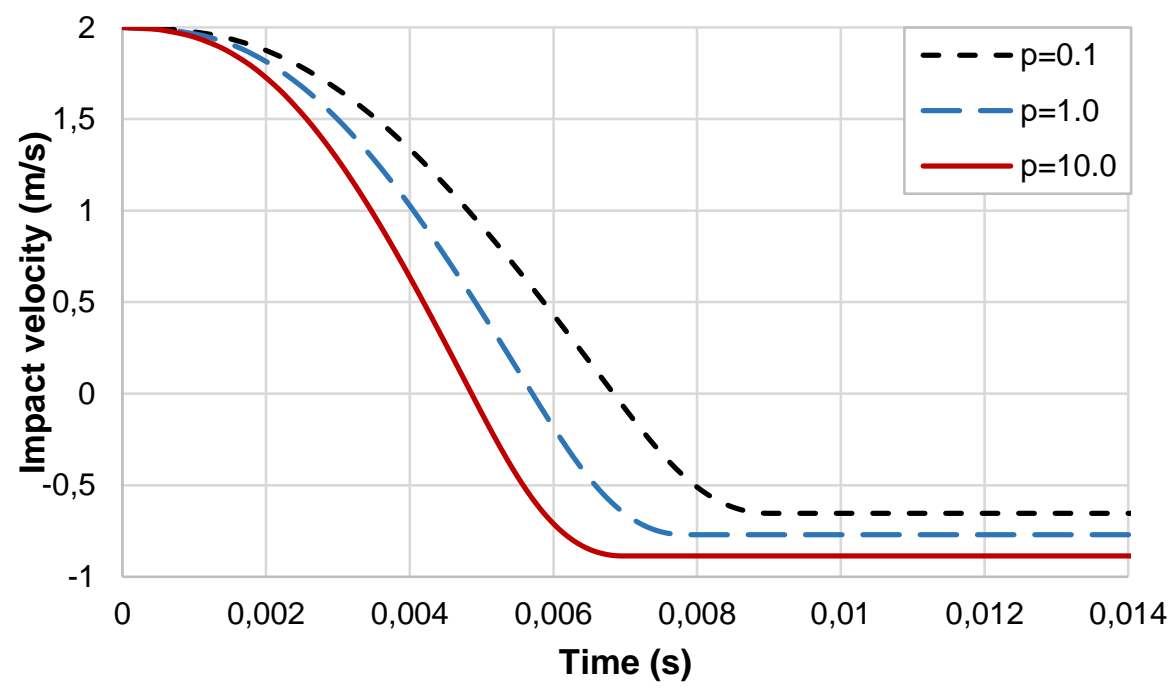

Figure 17. Temporal velocity responses for different power law index $\left(V_{0}=2 \mathrm{~m} / \mathrm{s}\right)$

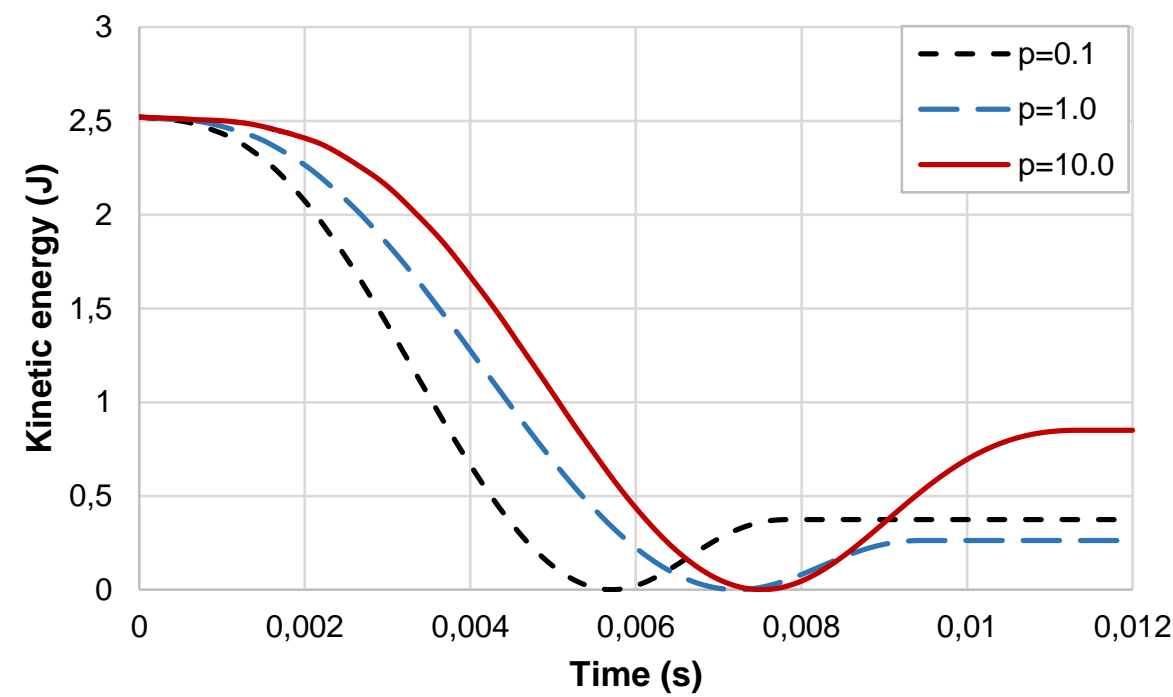

Figure 18. Temporal kinetic energy responses for different power law index $\left(V_{0}=2 \mathrm{~m} / \mathrm{s}\right)$ 


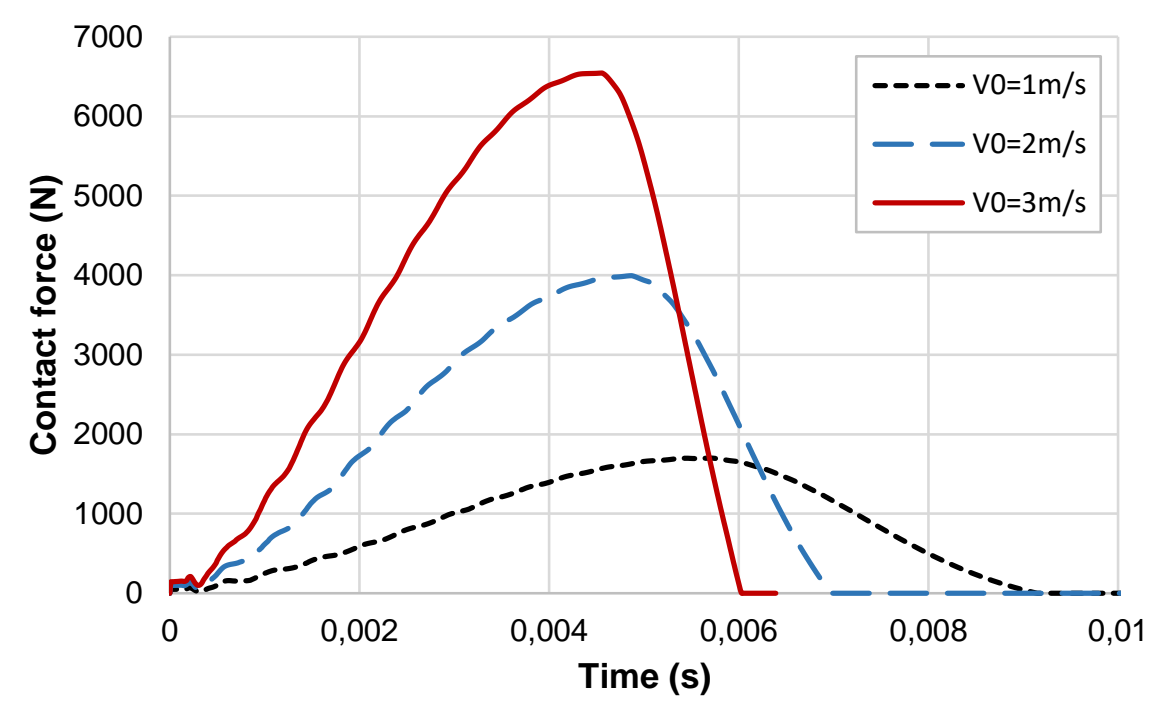

Figure 19. History contact force response for different velocities and $p=10.0$

\section{Conclusion}

In this work, a robust free-locking solid shell finite element is implemented in the interface UEL of ABAQUS in order to avoid numerical locking problems caused by conventional solid and shell elements. The formulation of the developed element is based on the coupling of ANS and EAS methods. To obtain current results, a modified FSDT with parabolic shape function was adopted.. Various benchmark tests are carried out with different geometries and materials to demonstrate the performance of the solid shell element. The application field is extended to analyze contact low velocity impact problem of FGM circular plates.

\section{References}

[1] Hou-Cheng H. Membrane locking and assumed strain shell elements. Computers \& Structures 1987;27:671-7. doi:10.1016/0045-7949(87)90083-6.

[2] Kui LX, Liu GQ, Zienkiewicz OC. A generalized displacement method for the finite element analysis of thin shells. International Journal for Numerical Methods in Engineering 1985;21:2145-55. doi:10.1002/nme.1620211203.

[3] Petchsasithon A, Gosling PD. A locking-free hexahedral element for the geometrically non-linear analysis of arbitrary shells. Computational Mechanics 2005;35:94-114. doi:10.1007/s00466-004-0604-y.

[4] Puso MA, Solberg J. A stabilized nodally integrated tetrahedral. International Journal for Numerical Methods in Engineering 2006;67:841-67. doi:10.1002/nme.1651.

[5] Klinkel S, Gruttmann F, Wagner W. A robust non-linear solid shell element based on a mixed variational formulation. Computer Methods in Applied Mechanics and Engineering 2006;195:179-201. doi:10.1016/j.cma.2005.01.013.

[6] Tan XG, Vu-Quoc L. Efficient and accurate multilayer solid-shell element: non-linear materials at finite strain. International Journal for Numerical Methods in Engineering 2005;63:2124-70. doi:10.1002/nme.1360.

[7] Bathe K, Dvorkin EN. A continuum mechanics based four-node shell element for general non-linear analysis. Engineering Computations 1984;1:77-88. doi:10.1108/eb023562.

[8] Simo JC, Rifai MS. A class of mixed assumed strain methods and the method of incompatible modes. International Journal for Numerical Methods in Engineering 1990;29:1595-638. doi:10.1002/nme.1620290802.

[9] Flores FG. A simple reduced integration hexahedral solid-shell element for large strains. Computer Methods in Applied Mechanics and Engineering 2016;303:260-87. doi:10.1016/j.cma.2016.01.013. 
[10] Hajlaoui A, Jarraya A, Kallel-Kamoun I, Dammak F. Buckling analysis of a laminated composite plate with delaminations using the enhanced assumed strain solid shell element. J Mech Sci Technol 2012;26:3213-21. doi:10.1007/s12206-012-0829-1.

[11] Rah K, Paepegem WV, Habraken AM, Degrieck J. A mixed solid-shell element for the analysis of laminated composites. International Journal for Numerical Methods in Engineering 2012;89:805-28. doi:10.1002/nme.3263.

[12] Li LM, Peng YH, Li DY. A stabilized underintegrated enhanced assumed strain solidshell element for geometrically nonlinear plate/shell analysis. Finite Elements in Analysis and Design 2011;47:511-8. doi:10.1016/j.finel.2011.01.001.

[13] Frikha A, Wali M, Hajlaoui A, Dammak F. Dynamic response of functionally graded material shells with a discrete double directors shell element. Composite Structures 2016;154:385-95. doi:10.1016/j.compstruct.2016.07.021.

[14] Hajlaoui A, Triki E, Frikha A, Wali M, Dammak F. Nonlinear Dynamics Analysis of FGM Shell Structures with a Higher Order Shear Strain Enhanced Solid-Shell Element. Latin American Journal of Solids and Structures 2017;14:72-91. doi:10.1590/1679-78253323.

[15] Jrad H, Mars J, Wali M, Dammak F. An extended finite element method for modeling elastoplastic FGM plate-shell type structures. STRUCTURAL ENGINEERING AND MECHANICS 2018;68:299-312.

[16] Jrad H, Mars J, Wali M, Dammak F. Geometrically nonlinear analysis of elastoplastic behavior of functionally graded shells. Engineering with Computers 2018. doi:10.1007/s00366-018-0633-3.

[17] Mallek H, Jrad H, Wali M, Dammak F. Piezoelastic response of smart functionally graded structure with integrated piezoelectric layers using discrete double directors shell element. Composite Structures 2019;210:354-66. doi:10.1016/j.compstruct.2018.11.062.

[18] Mars J, Koubaa S, Wali M, Dammak F, Mars J, Koubaa S, et al. Numerical Analysis of Geometrically Non-Linear Behavior of Functionally Graded Shells. Latin American Journal of Solids and Structures 2017;14:1952-78. doi:10.1590/1679-78253914.

[19] Mellouli H, Jrad H, Wali M, Dammak F. Meshfree implementation of the double director shell model for FGM shell structures analysis. Engineering Analysis with Boundary Elements 2019;99:111-21. doi:10.1016/j.enganabound.2018.10.013.

[20] Wali M, Hentati T, Jarraya A, Dammak F. Free vibration analysis of FGM shell structures with a discrete double directors shell element. Composite Structures 2015;125:295-303. doi:10.1016/j.compstruct.2015.02.032.

[21] Zghal S, Frikha A, Dammak F. Free vibration analysis of carbon nanotube-reinforced functionally graded composite shell structures. Applied Mathematical Modelling 2018;53:132-55. doi:10.1016/j.apm.2017.08.021.

[22] Hajlaoui A, Jarraya A, El Bikri K, Dammak F. Buckling analysis of functionally graded materials structures with enhanced solid-shell elements and transverse shear correction. Composite Structures 2015;132:87-97. doi:10.1016/j.compstruct.2015.04.059.

[23] Reinoso J, Blázquez A. Geometrically nonlinear analysis of functionally graded powerbased and carbon nanotubes reinforced composites using a fully integrated solid shell element. Composite Structures 2016;152:277-94. doi:10.1016/j.compstruct.2016.05.036.

[24] Chalal H, Abed-Meraim F. Quadratic Solid-Shell Finite Elements for Geometrically Nonlinear Analysis of Functionally Graded Material Plates. Materials 2018;11:1046. doi:10.3390/ma11061046.

[25] DHATT G. Numerical Analysis of Thin Shells by Curved Triangular Elements Based on Discrete Kirchhoff Hypothesis. Proc ASCE, Symp on Applications of FEM in Civil Engineering, Vanderbilt Univ, Nashville, Tenn, 1969 1969:13-4.

[26] MINDLIN RD. Influence of Rotatory Inertia and Shear on Flexural Motions of Isotropic, Elastic Plates. J Appl Mech 1951;18:31-8. 
[27] Murthy MVV. An improved transverse shear deformation theory for laminated antisotropic plates. 1981.

[28] Mellouli H, Jrad H, Wali M, Dammak F. Meshless implementation of arbitrary 3D-shell structures based on a modified first order shear deformation theory. Computers \& Mathematics with Applications 2019;77:34-49. doi:10.1016/j.camwa.2018.09.010.

[29] Trabelsi S, Frikha A, Zghal S, Dammak F. Thermal post-buckling analysis of functionally graded material structures using a modified FSDT. International Journal of Mechanical Sciences 2018;144:74-89. doi:10.1016/j.ijmecsci.2018.05.033.

[30] BeikMohammadlou H, EkhteraeiToussi H. Parametric studies on elastoplastic buckling of rectangular FGM thin plates. Aerospace Science and Technology 2017;69:513-25. doi:10.1016/j.ast.2017.07.015.

[31] Huang H, Zhang Y, Han Q. Inelastic Buckling of FGM Cylindrical Shells Subjected to Combined Axial and Torsional Loads. International Journal of Structural Stability and Dynamics 2017;17:1771010. doi:10.1142/S0219455417710109.

[32] Vaghefi R, Hematiyan MR, Nayebi A. Three-dimensional thermo-elastoplastic analysis of thick functionally graded plates using the meshless local Petrov-Galerkin method. Engineering Analysis with Boundary Elements 2016;71:34-49. doi:10.1016/j.enganabound.2016.07.001.

[33] Zhang J, Qi D, Zhou L, Zhao L, Hu N. A progressive failure analysis model for composite structures in hygrothermal environments. Composite Structures 2015;133:331-42. doi:10.1016/j.compstruct.2015.07.063.

[34] Doghri I, Ouaar A. Homogenization of two-phase elasto-plastic composite materials and structures: Study of tangent operators, cyclic plasticity and numerical algorithms. International Journal of Solids and Structures 2003;40:1681-712. doi:10.1016/S00207683(03)00013-1.

[35] Ponte Castañeda P. Second-order homogenization estimates for nonlinear composites incorporating field fluctuations: I- theory. Journal of the Mechanics and Physics of Solids 2002;50:737-57. doi:10.1016/S0022-5096(01)00099-0.

[36] Suquet P. Effective Properties of Nonlinear Composites. In: Suquet P, editor. Continuum Micromechanics, Vienna: Springer Vienna; 1997, p. 197-264. doi:10.1007/978-3-70912662-2_4.

[37] Mori T, Tanaka K. Average stress in matrix and average elastic energy of materials with misfitting inclusions. Acta Metallurgica 1973;21:571-4. doi:10.1016/00016160(73)90064-3.

[38] Bao G, Wang L. Multiple cracking in functionally graded ceramic/metal coatings. International Journal of Solids and Structures 1995;32:2853-71. doi:10.1016/00207683(94)00267-Z.

[39] Abida M, Mars J, Gehring F, Vivet and Fakhreddine Dammak A. Anisotropic ViscoElastoplastic Modeling of Quasi-Unidirectional Flax Fiber Reinforced Epoxy Behavior: An Investigation on Low-Velocity Impact Response. Journal of Renewable Materials 2018;6:464-76. doi:10.32604/JRM.2018.01897.

[40] Koubaa S, Mars J, Wali M, Dammak F. Numerical study of anisotropic behavior of Aluminum alloy subjected to dynamic perforation. International Journal of Impact Engineering 2017;101:105-14. doi:10.1016/j.ijimpeng.2016.11.017.

[41] Mars J, Wali M, Jarraya A, Dammak F, Dhiab A. Finite element implementation of an orthotropic plasticity model for sheet metal in low velocity impact simulations. ThinWalled Structures 2015;89:93-100. doi:10.1016/j.tws.2014.12.019.

[42] Mars J, Chebbi E, Wali M, Dammak F. Numerical and experimental investigations of low velocity impact on glass fiber-reinforced polyamide. Composites Part B: Engineering 2018;146:116-23. doi:10.1016/j.compositesb.2018.04.012. 
[43] Mars J, Said LB, Wali M, Dammak F. Elasto-Plastic Modeling of Low-Velocity Impact on Functionally Graded Circular Plates. Int J Appl Mechanics 2018;10:1850038. doi:10.1142/S1758825118500382.

[44] Gunes R, Aydin M, Kemal Apalak M, Reddy JN. Experimental and numerical investigations of low velocity impact on functionally graded circular plates. Composites Part B: Engineering 2014;59:21-32. doi:10.1016/j.compositesb.2013.11.022.

[45] Chi S-H, Chung Y-L. Mechanical behavior of functionally graded material plates under transverse load-Part I: Analysis. International Journal of Solids and Structures 2006;43:3657-74. doi:10.1016/j.ijsolstr.2005.04.011.

[46] Belhassen L, Koubaa S, Wali M, Dammak F. Anisotropic effects in the compression beading of aluminum thin-walled tubes with rubber. Thin-Walled Structures 2017;119:902-10. doi:10.1016/j.tws.2017.08.010.

[47] Bouhamed A, Jrad H, Said LB, Wali M, Dammak F. A non-associated anisotropic plasticity model with mixed isotropic-kinematic hardening for finite element simulation of incremental sheet metal forming process. The International Journal of Advanced Manufacturing Technology 2019;100:929-40. doi:10.1007/s00170-018-2782-3.

[48] Klinkel S, Gruttmann F, Wagner W. A continuum based three-dimensional shell element for laminated structures. Computers \& Structures 1999;71:43-62. doi:10.1016/S00457949(98)00222-3.

[49] Timoshenko SP, Woinosky-Krieger S. Theory of plates and shells. 2nd ed. New York: McGraw-Hill; 1959.

[50] Duarte Filho LA, Awruch AM. Geometrically nonlinear static and dynamic analysis of shells and plates using the eight-node hexahedral element with one-point quadrature. Finite Elements in Analysis and Design 2004;40:1297-315. doi:10.1016/j.finel.2003.08.012.

[51] Arciniega RA, Reddy JN. Large deformation analysis of functionally graded shells. International Journal of Solids and Structures 2007;44:2036-52. doi:10.1016/j.ijsolstr.2006.08.035.

[52] Sze KY, Liu XH, Lo SH. Popular benchmark problems for geometric nonlinear analysis of shells. Finite Elements in Analysis and Design 2004;40:1551-69. doi:10.1016/j.finel.2003.11.001.

[53] Chen LB, Xi F, Yang JL. Elastic-plastic contact force history and response characteristics of circular plate subjected to impact by a projectile. Acta Mech Sin 2007;23:415-25. doi:10.1007/s10409-007-0084-3. 